\title{
Post-noon two-minute period pulsating aurora and their relationship to the dayside convection pattern
}

\author{
S. E. Milan ${ }^{1}$, T. K. Yeoman ${ }^{1}$, M. Lester ${ }^{1}$, J. Moen $^{2}$, P. E. Sandholt ${ }^{3}$ \\ ${ }^{1}$ Department of Physics and Astronomy, University of Leicester, Leicester LE1 7RH, UK \\ E-mail: ets@ion.le.ac.uk \\ ${ }^{2}$ UNIS, PO Box 156, N-9170 Longyearbyen, Norway \\ ${ }^{3}$ Department of Physics, University of Oslo, PO Box 1048 Blindern, N-0316 Oslo, Norway
}

Received: 8 October 1998 / Revised: 12 February 1999 / Accepted: 23 February 1999

\begin{abstract}
Poleward-moving auroral forms, as observed by meridian-scanning photometers, in the vicinity of the cusp region are generally assumed to be the optical signature of flux transfer events. Another class of quasicontinuous, short period (1-2 min) wave-like auroral emission has been identified, closely co-located with the convection reversal boundary in the post-noon sector, which is similar in appearance to such cusp aurora. It is suggested that these short period wave-like auroral emissions, the optical signature of boundary plasma sheet precipitation in the region 1 field-aligned current system, are associated with ULF magnetohydrodynamic wave activity, which is observed simultaneously by ground magnetometer stations. This association with ULF wave activity is strengthened by the observation of several harmonic frequencies in the pulsation spectrum, each an overtone of the fundamental standing wave resonance frequency.
\end{abstract}

Key words. Magnetospheric physics (auroral phenomena; magnetopause, cusp, and boundary layers; MHD waves and instabilities)

\section{Introduction}

A recent study of optical and radar aurora in the vicinity of the cusp region (Milan et al., 1999) indicated the presence of quasi-periodic poleward-moving auroral forms (PMAFs) associated with enhancements of the convection velocity. Whilst bearing some similarity to the expected optical signature of flux transfer events (Sandholt et al., 1986; Fasel, 1995; Øieroset et al., 1996, 1997; Farrugia et al., 1998), Milan et al. (1999) suggested that the highly wave-like nature and 2 min period-

Correspondence to: S. E. Milan icity of the PMAFs were inconsistent with the typical repetition rate of transient reconnection. The study of Milan et al. (1999) was based on the first day of an eight day experimental campaign conducted between 17 and 25 December, 1995. Subsequently it was found that this short period wave-like auroral phenomenon is a common feature of dayside optical emission, being present on 5 out of the 8 campaign days. The present study employs observations of the red and green line emission by a meridian-scanning photometer located at $\mathrm{Ny}$ Alesund, Svalbard, Norway, from 18 December 1995, to investigate these PMAFs in more detail.

Plasma drift measurements from the CUTLASS Finland coherent HF radar allow the optical observations to be placed within the context of the dayside convection pattern. Ground-based magnetometers from the IMAGE network are employed to determine the relationship between the auroral observations and ULF wave activity in the magnetic field. Supporting observations are provided by a white light all-sky camera located at Longyearbyen, Svalbard, and low-altitude particle precipitation measurements from the polarorbiting DMSP F13 satellite.

\section{Experimental arrangement}

The SuperDARN coherent HF radars (Greenwald et al., 1995) employ backscatter from high-latitude field-aligned ionospheric plasma density irregularities (radar aurora) as tracers of the bulk plasma motion under the influence of the convection electric field, and hence as a diagnostic tool for the investigation of largescale magnetosphere-ionosphere coupling. The Co-operative UK Twin Located Auroral Sounding System (CUTLASS) forms the eastern-most pair of radars of SuperDARN, of which the Finland radar, located at Hankasalmi $\left(62.3^{\circ} \mathrm{N}, 26.6^{\circ} \mathrm{E}\right)$, is the focus of the present study (see Fig. 1). Sixteen beams are sounded sequentially with a dwell time of $7 \mathrm{~s}$, completing a $52^{\circ}$ azimuth scan every $2 \mathrm{~min}$. Seventy-five range gates are sampled for each beam, with a gate length of $45 \mathrm{~km}$ and a range 


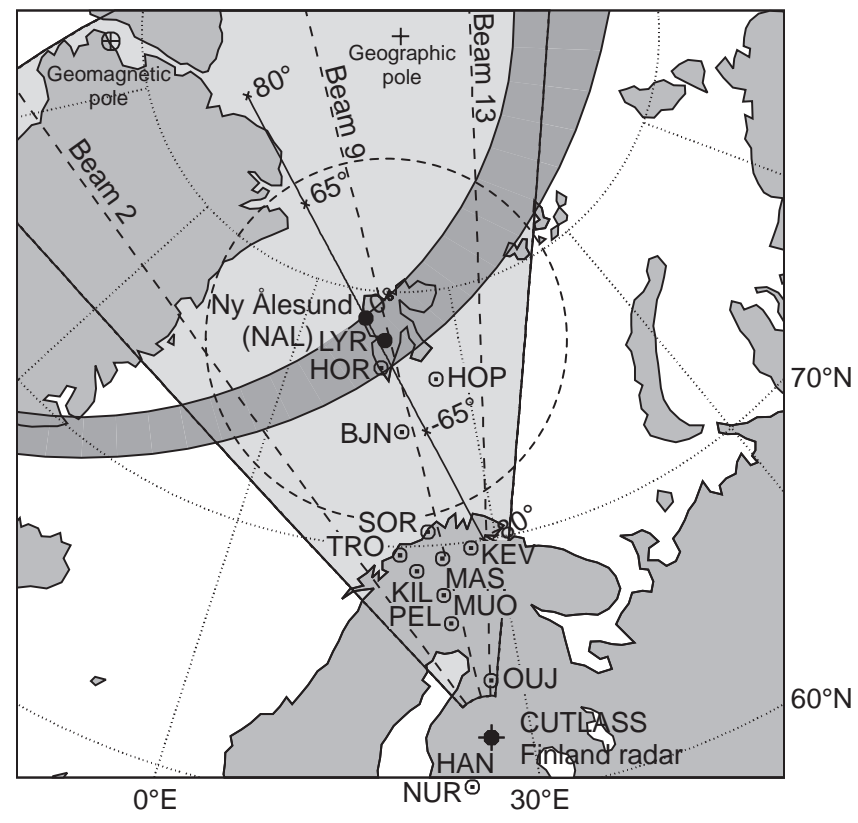

Fig. 1. The location of the field-of-view of the CUTLASS Finland radar; beams 2, 9, and 13 are indicated by dashed lines. The $\mathrm{Ny}$ Allesund MSP meridian, projected to an altitude of $300 \mathrm{~km}$, and the field-of-view of the Longyearbyen ASC are also indicated, as are the 15 IMAGE ground magnetometer stations employed in the study. The approximate location of the dayside auroral oval for quiet conditions is superimposed for context

to the first gate of $180 \mathrm{~km}$. A 7 pulse scheme is transmitted, and analysis of the auto-correlation function of the returned signals yields backscatter Doppler spectra, from which the mean Doppler velocity, an estimate of the line-of-sight plasma drift velocity, and special width can be derived.

The meridian-scanning photometer (MSP) located at Ny Ålesund $\left(78.9^{\circ} \mathrm{N}, 11.9^{\circ} \mathrm{E}\right)$ Svalbard, scans roughly along the magnetic meridian, $35^{\circ}$ west of geographic north, to $10^{\circ}$ above the northern and southern horizons, with a scan period of $18 \mathrm{~s}$. The meridian closely follows beam 9 of the CUTLASS Finland radar (see Fig. 1). The line-of-sight intensities of $630.0 \mathrm{~nm}$ (red line) and $557.7 \mathrm{~nm}$ (green line) auroral emissions are measured, corresponding to transitions from the ID and IS metastable states of atomic oxygen (OI). The red line emissions can have an altitude of peak emission intensity between $250 \mathrm{~km}$ and $550 \mathrm{~km}$, excited by electrons of energies of order $100 \mathrm{eV}$. In the present study, a red line emission altitude of $300 \mathrm{~km}$ is assumed, as this gives an excellent correspondence between the location of the aurora and the radar backscatter (see Sect. 3.3). Green line emissions are generally assumed to originate from an altitude between $110 \mathrm{~km}$ and $150 \mathrm{~km}$ (Sigernes et al., 1996) However, in the present study, it is found that an emission altitude of $200 \mathrm{~km}$ for the green line gives an exact match between the red and green line observations; this will be discussed in Sect. 4. In addition, observations from a white light all-sky camera (ASC) located at Longyearbyen $\left(78.1^{\circ} \mathrm{N}, 16.0^{\circ} \mathrm{E}\right)$, Svalbard, are employed to allow the azimuthal extent of auroral features to be determined. The approximate extent of the ASC field-of-view is illustrated in Fig. 1.

Fifteen IMAGE magnetometer stations were also employed in the study (see Fig. 1) $X, Y$ and $Z$ geographic component magnetic field direction measurements were made with a sampling resolution of $10 \mathrm{~s}$. Most stations had a resolution of $1 \mathrm{nT}$, though the three lowest latitude stations, OUJ, HAN, and NUR, have a resolution of $0.1 \mathrm{nT}$. The measurements presented in this study have been rotated such that the $X_{\text {mag }}$ and $Y_{\text {mag }}$ coordinate axes are positive towards geomagnetic (IGRF) north and east, respectively.

\section{Observations}

The bulk of observations discussed in the present study were made between 0900 and 1300 UT, 18 December 1995. During this interval the ground-based instrumentation was located in the noon and post-noon sectors, the MSP meridian progressing from 12 MLT to 16 MLT. Near winter solstice, Svalbard is in darkness even at local noon, allowing optical observations of the cusp and other dayside auroral regions to be made.

\subsection{Solar wind and interplanetary magnetic field observations}

During the period of interest the WIND spacecraft was located upstream of the Earth's bowshock, near ( $X_{\mathrm{GSM}}$, $\left.Y_{\mathrm{GSM}}, Z_{\mathrm{GSM}}\right)=\left(49 R_{e}, 34 R_{e}, 0 R_{e}\right)$. The interplanetary magnetic field (IMF) observations showed a southward turning at 0920 UT after which $B_{z}$ remained negative, varying between -3 and $-4 \mathrm{nT}$, for the remainder of the interval, except for a brief return to $B_{z} \approx 0 \mathrm{nT}$ at $1000 \mathrm{UT}$. The $B_{y}$ component varied between 0 and $2 \mathrm{nT}$ throughout this interval except for a brief excursion to $-3 \mathrm{nT}$ at $1000 \mathrm{UT}$, and $B_{x}$ varied between 0 and $2 \mathrm{nT}$. The solar wind speed and density were of the order of $-350 \mathrm{~km} \mathrm{~s}^{-1}$ and 4 protons $\mathrm{cm}^{-3}$. A solar wind delay of some $12 \mathrm{~min}$ is expected between the spacecraft and the bowshock. A further 5 to 10 min delay is then possible to the ionospheric footprint of the cusp region.

\subsection{Radar observations}

The top six panels of Fig. 2 illustrate the line-of-sight Doppler velocity measurements and the backscatter spectral width from beams 2, 9 and 13 of the CUTLASS Finland radar, between 0930 UT and 1300 UT. Positive (negative) velocities represent motion towards (away from) the radar. Significant radar backscatter was first observed shortly after 0930 UT, possibly in response to the southward turning of the IMF observed to the WIND spacecraft at 0920 UT. Most ionospheric backscatter of interest occurred between geomagnetic latitudes of approximately $75^{\circ}$ and $81^{\circ}$ in the AACGM (altitude adjusted, corrected geomagnetic) coordinate system (Baker and Wing, 1989). As the dusk solar terminator swept westward across the radar field-of- 

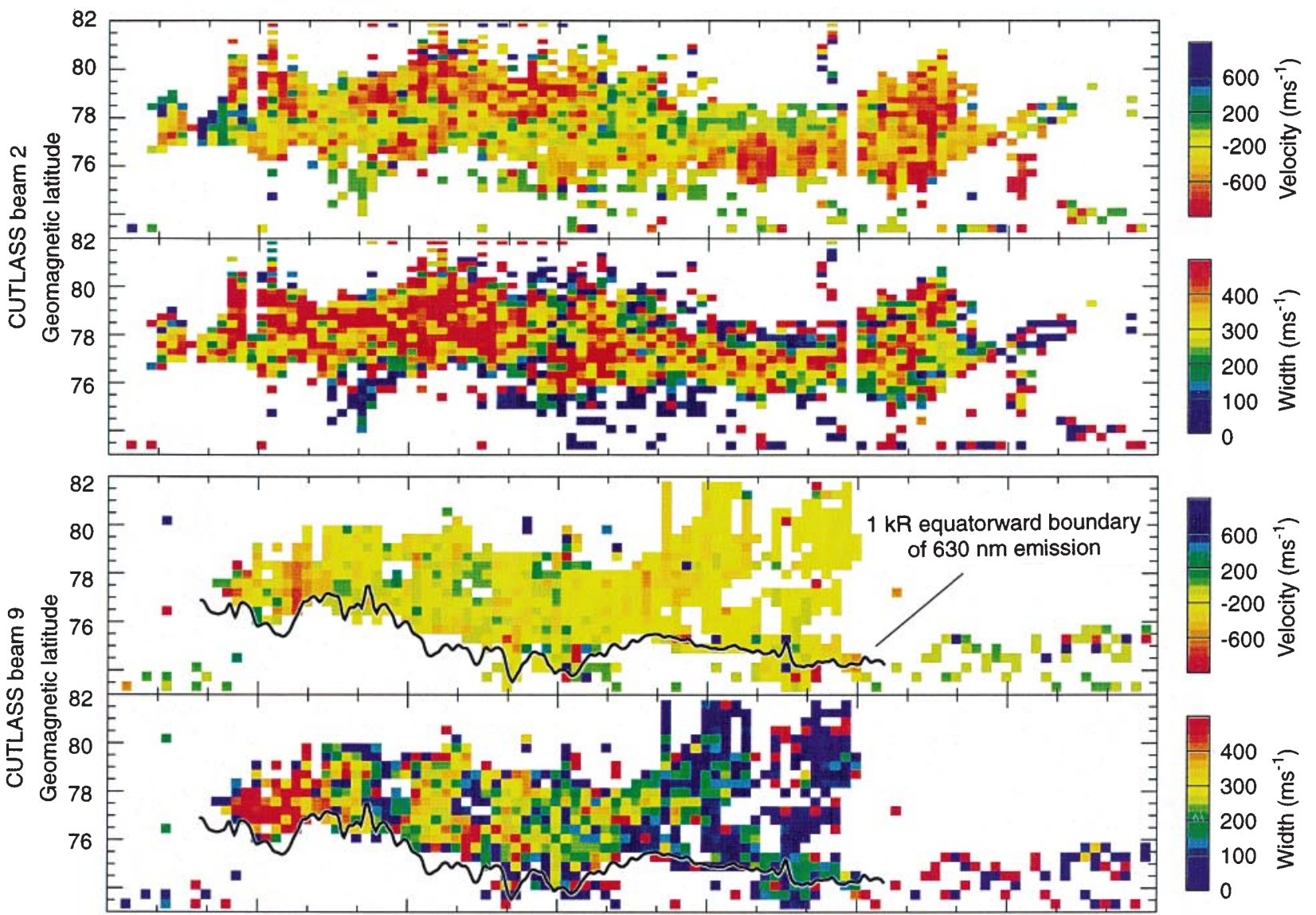

影

i

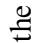

竞

$\stackrel{\square}{\square}$

$\frac{\mathscr{8}}{\frac{0}{0}}$

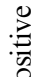

2
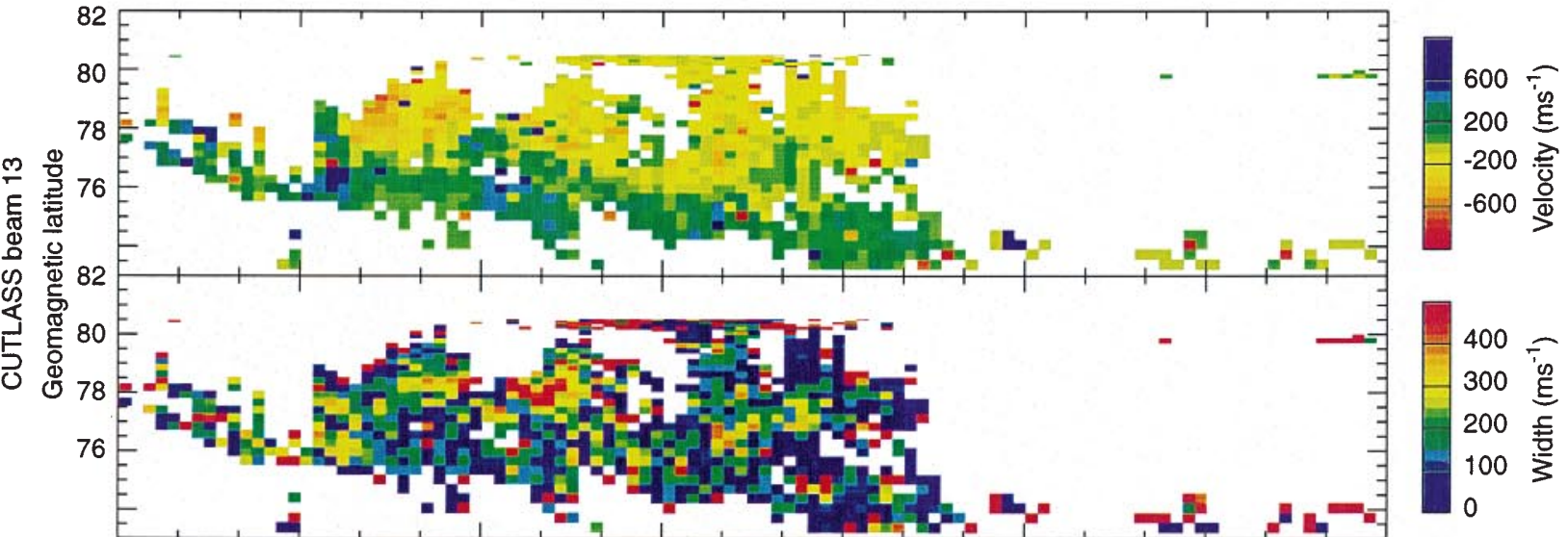

중
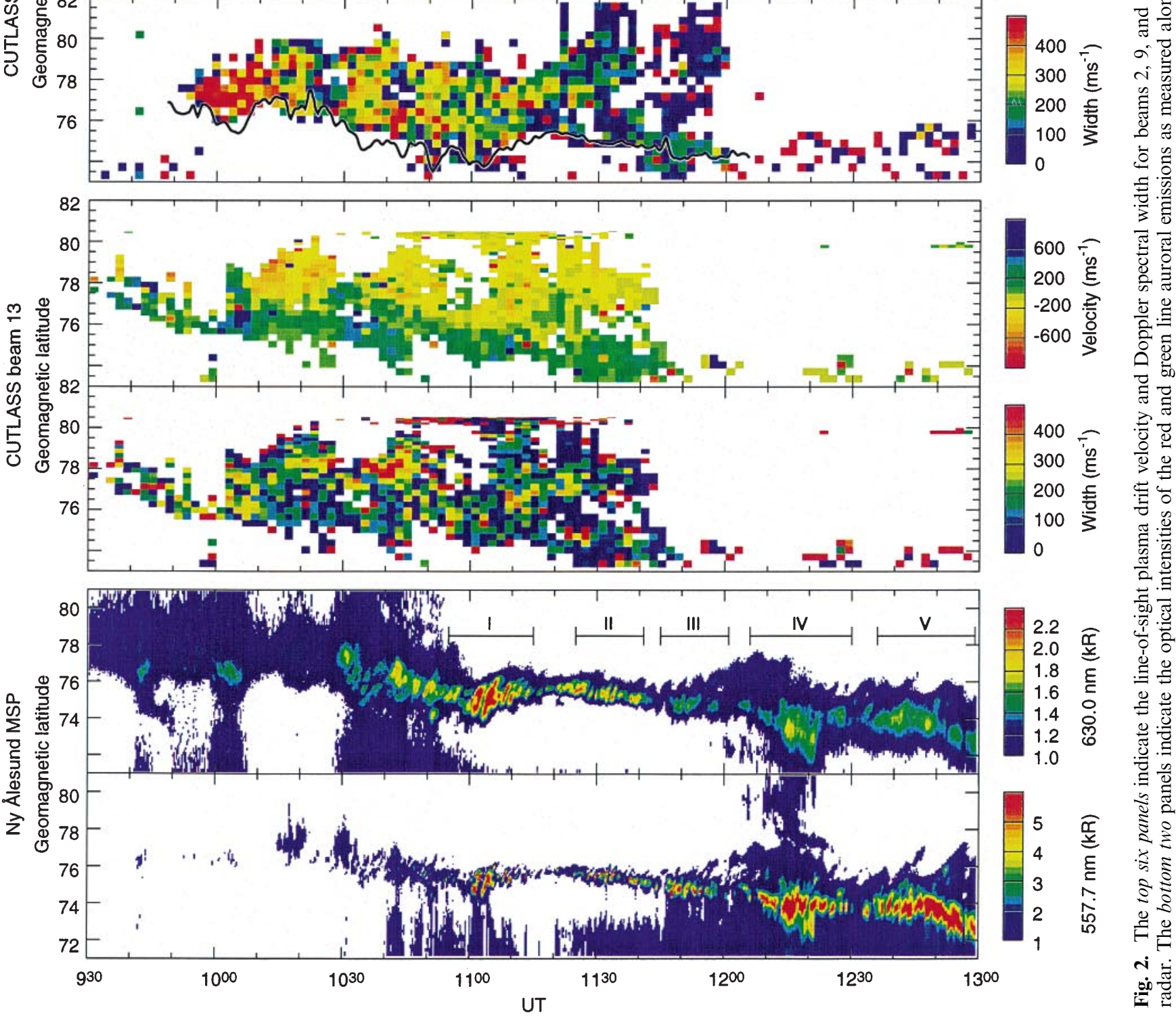

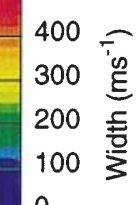

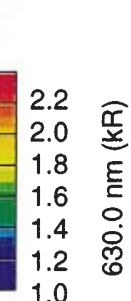

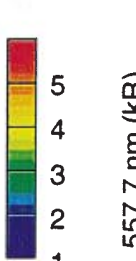

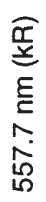

:

نํ. 
view between 1130 UT and 1300 UT, HF propagation to far ranges was no longer supported and ionospheric backscatter was lost at 1150 UT, 1200 UT and 1230 UT in beams 13, 9 and 2, respectively.

Beam 2 observes predominantly negative line-of-sight velocities, indicative of poleward and westward plasma drift, and high spectral widths, above $400 \mathrm{~ms}^{-1}$. In beam 9 , the line-of-sight drift velocity is generally slower than that observed in beam 2, though as the beam closely follows a magnetic meridian all information regarding the azimuthal component of the flow is lost. Between $0950 \mathrm{UT}$ and $1020 \mathrm{UT}$, the observed spectral width is high, above $400 \mathrm{~ms}^{-1}$. After 1020 UT the spectral width falls in general to below $300 \mathrm{~ms}^{-1}$ and after 1130 UT to $200 \mathrm{~ms}^{-1}$. Beam 13 indicates the presence of a convection flow reversal, positive and negative velocities being observed equatorward and poleward of approximately $77^{\circ}$ CGMLAT. This corresponds to azimuthal flow, eastward at higher latitudes and westward at lower latitudes. The spectral width is in general low, mainly below $300 \mathrm{~ms}^{-1}$, at all times in beam 13. Examination of spatial maps from the interval, of which that presented in Fig. 3 is a typical example, help clarify the flow pattern. The observed line-of-sight velocities are consistent with a convection reversal in the post-noon sector, near a latitude of $77^{\circ}$, flow being sunward (westward) at lower latitudes and antisunward (eastward) at higher latitudes. In this region, the spectral widths are low, less than $300 \mathrm{~ms}^{-1}$ in general. In the noon sector, the observed flows are consistent with westward and antisunward plasma drift and the spectral width is high, above $400 \mathrm{~ms}^{-1}$ in general.

Figure 4 reproduces ion and electron spectrograms observed during an overpass of the DMSP F13 satellite from east to west through the radar field-of-view between 1022 UT and 1036 UT. Along the satellite track (illustrated in Fig. 3) regions of central plasma sheet (CPS), boundary plasma sheet (BPS) and mantle precipitation can be identified from the criteria of Newell et al. (1991). These regions (CPS: orange; BPS: red; mantle: blue/green) have been indicated at the top of Fig. 4 and along the satellite track of Fig. 3; gaps between these regions correspond to portions of the spectrograms that are deemed "void" or "unclear" by the Newell et al. (1991) criteria. The transition from BPS to mantle precipitation, i.e. the boundary between closed and open field lines, is closely co-located with the convection reversal boundary observed by the CUTLASS radar in the post-noon sector. It is also suggested that the sunward flow region of the radar backscatter is associated with BPS precipitation, and no backscatter appears at the ionospheric footprint of the CPS region. Examination of the spectrograms from this overpass suggests that the mantle precipitation region can be further subdivided, a marked increase in the flux of low energy ions (indicated in green) being coincident with the noon sector region of high spectral width backscatter.

The flow pattern surmised from the observations is sketched schematically in Fig. 5. This pattern is found to remain highly stable throughout the interval from 0950 UT to 1200 UT or later, concordant with the
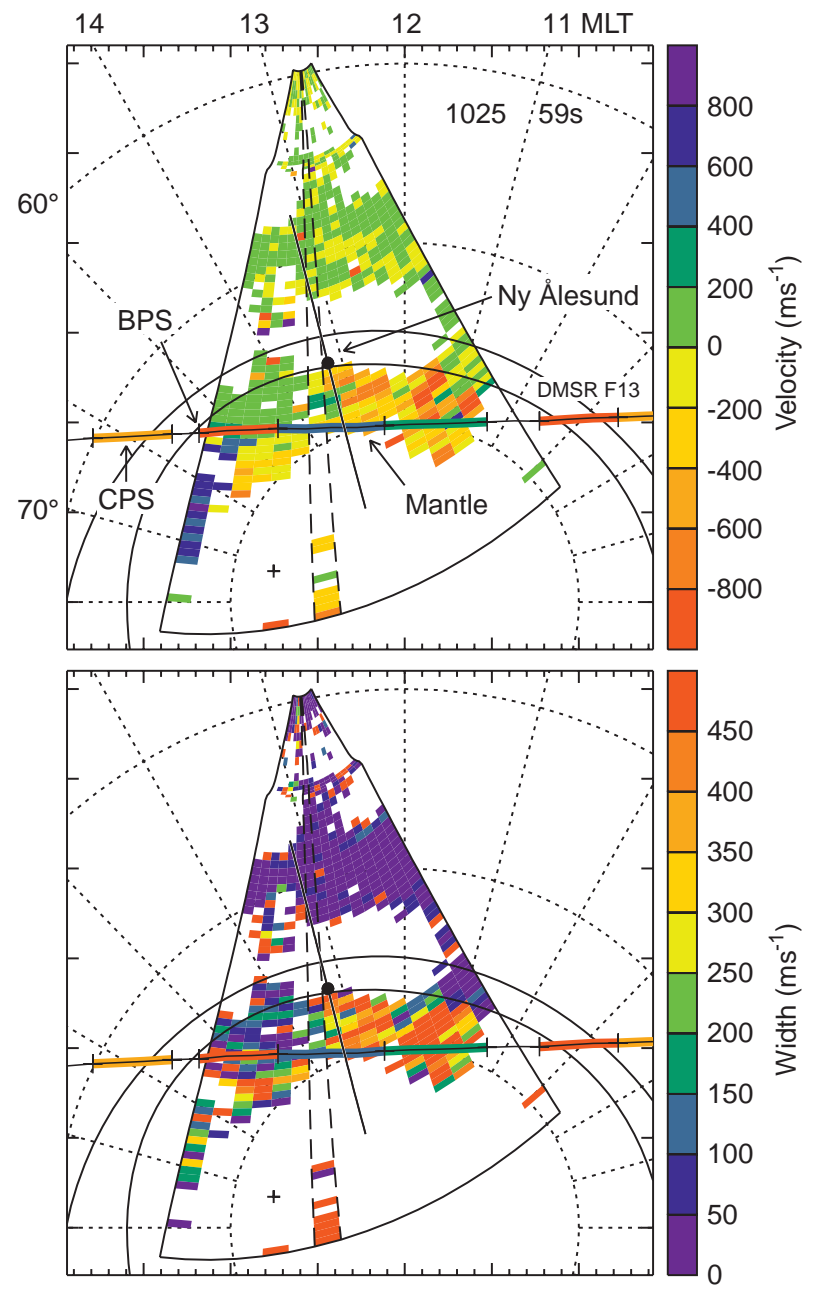

Fig. 3. The line-of-sight velocity and spectral width observed by the radar during the scan starting $1026 \mathrm{UT}$, projected onto geomagnetic latitude and local time coordinate axes; backscatter with low velocity and spectral width equatorward of $72^{\circ}$ CGMLAT is ground backscatter and of no interest to the present study. The location of the statistical auroral oval is included, as well as the $300 \mathrm{~km}$ projection of the Ny Ålesund MSP meridian. Beam 9 of the radar is indicated by dashed lines. Overlaid is the east-west pass of DMSP F13 between 1023 UT and 1034 UT

relatively uniform nature of the IMF during this period. Variations in the measurements made by the radar are due principally to the rotation of the Earth under this stable convection pattern and the progression of the radar field-of-view to later local times. For instance, the decrease in spectral width observed in beam 9 near 1020 UT (Fig. 2) corresponds to the edge of the noon sector high spectral width region, located near 0130 to 0200 MLT (Fig. 3).

\subsection{Optical observations}

Between 0900 UT and 1300 UT the MSP meridian was located between 12 MLT and 16 MLT. The auroral observations for this interval are illustrated in the bottom two panels of Fig. 2, and have been projected 

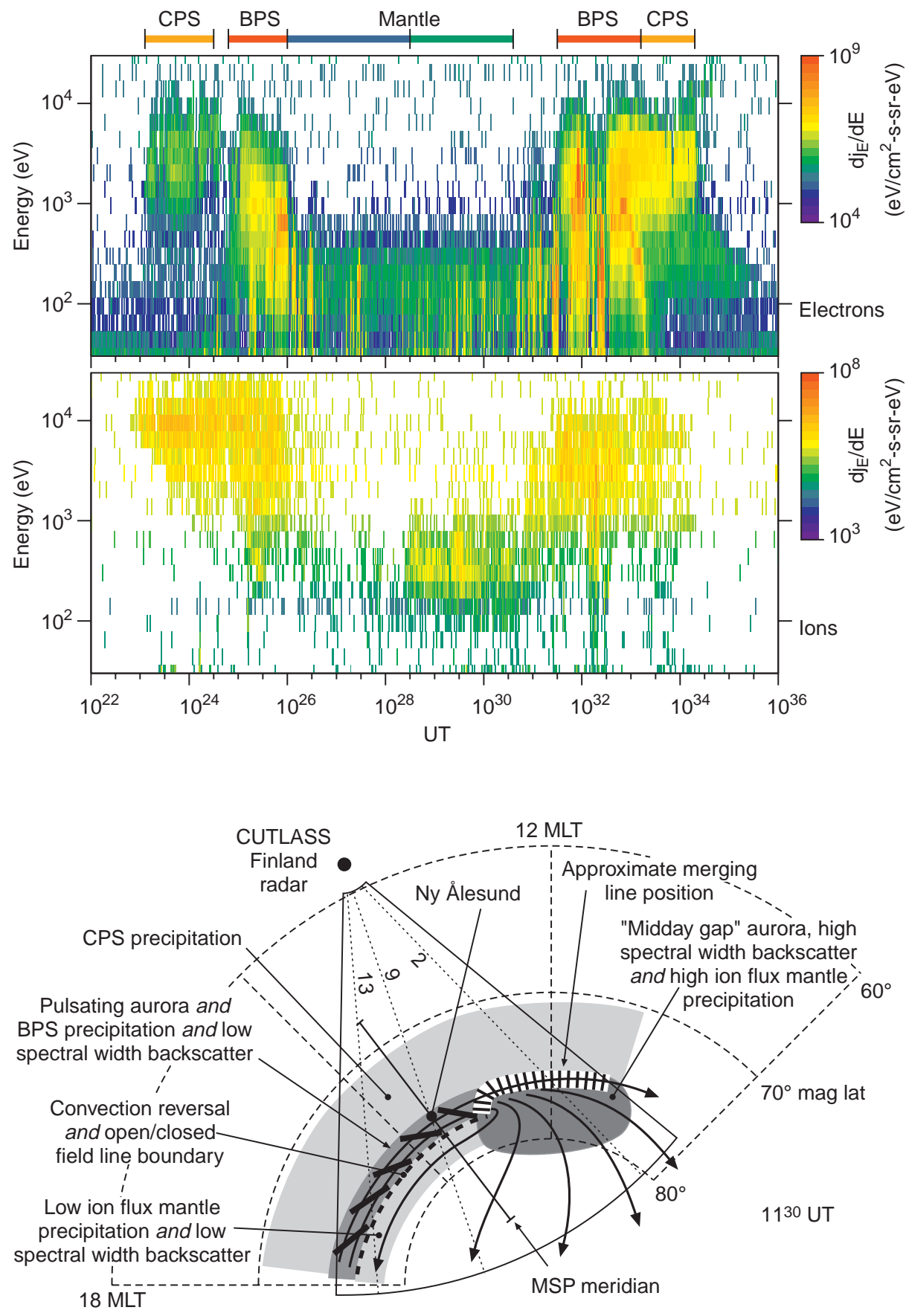

Fig. 4. Ion and electron spectrograms from the overpass of DMSP F13. Regions of CPS, BPS and mantle precipitation are indicated at the top of the figure, in orange, red and blue/green, respectively. Blue and green correspond to low and high fluxes of low energy ions in the mantle precipitation region
Fig. 5. A schematic representation of the radar and optical observations for the interval of study. The radar field-of-view and MSP meridian are indicated for 1130 UT. The pulsating aurora are observed co-located with BPS precipitation, located between the post-noon convection reversal boundary and the equatorward boundary of the radar aurora to a geomagnetic latitude frame by assuming peak emission altitudes of $300 \mathrm{~km}$ and $200 \mathrm{~km}$ for the red and green lines, respectively. Prior to approximately 1030 UT the aurora are diffuse and weak, the red line peaking at an intensity of some $1.5 \mathrm{kR}$, and the green line barely visible above the ambient background glow, an auroral configuration known as the "midday gap" (Dandekar and Pike, 1978). After 1030 UT the auroral emission intensity increases in both lines. Between 1030 UT and approximately $1130 \mathrm{UT}$, the intensities in the two lines are comparable, peaking between 3 and $6 \mathrm{kR}$. After 1130 UT, however, the intensity in the red line diminishes to below $2 \mathrm{kR}$ and the green line is enhanced, peaking near $10 \mathrm{kR}$.
The region of main auroral emission occupies a latitudinal region which varies in width between approximately $0.5^{\circ}$ and $1.5^{\circ}$, and has a general equatorward progression from $78^{\circ}$ at $1030 \mathrm{UT}$ to $72.5^{\circ}$ at 1300 UT. In Fig. 2, the radar data for beam 9, the beam most aligned with the MSP meridian, has superimposed on it the equatorward boundary of the red line aurora as determined from the latitude at which the emission intensity falls to $1 \mathrm{kR}$, for the period $0950 \mathrm{UT}$ to 1205 UT. Throughout this interval, an excellent agreement is found between the locations of the equatorward boundaries of the radar and optical aurora, confirming the assumed emission altitude of the red line aurora of $300 \mathrm{~km}$. Also, importantly, this co-location is found 
between 1000 UT and 1030 UT, when the equatorward boundary of the red line aurora is overhead the MSP zenith and hence the mapping of its location is independent of the assumed emission altitude.

Throughout the interval 1030 UT to 1300 UT, the red and green aurora take the form of poleward-moving intensity enhancements which have a duration and repetition rate near $2 \mathrm{~min}$. A closer examination suggests that these poleward-moving forms are wave-like in nature and occur in wave packets. Five such packets, numbered $\mathrm{I}$ to $\mathrm{V}$, have been indicated in Fig. 2 and are reproduced in more detail in Fig. 6. For the first three intervals, both the red and green line emission intensities are illustrated; in the case of intervals IV and V, only the green line observations are shown as the red line emissions are weak and show no significant structure. The correspondence between the variations in the red and green lines in examples I to III suggests that the emissions are excited by a single source of precipitating particles with a relatively broad range of energies. It also gives confidence in the $200 \mathrm{~km}$ assumed emission altitude of the green line observations in this study. Each wave packet tends to be between 7 and 10 cycles in duration. To the eye, each wave packet, especially I, II, IV, and the first half of $\mathrm{V}$, displays a near $180^{\circ}$ phase change in the emission intensity variation across the central latitude of the wave structure. The green line observation of wave packet II, being perhaps the most well-defined example, is illustrated in more detail in Fig. 7. The emission intensities measured at the $26 \mathrm{MSP}$ scan positions which map to latitudes between $78.1^{\circ}$ and $78.9^{\circ}$ for the interval 1127 UT to 1137 UT are indicated in Fig. 7a. The self-normalised Fourier spectra of each time series, illustrated in Fig. 7b, indicate that the predominant spectral component is $12.2 \mathrm{mHz}(82 \mathrm{~s})$ at all latitudes. The relative spectral power and phase in this component are indicated as a function of latitude in Fig. 7c, d respectively, and confirm the intensity and phase structure of the wave discussed. A similar analysis of wave packet IV shows that its more complicated structure is produced by the mixing of several frequency components, $7.1 \mathrm{mHz}$ and $14.1 \mathrm{mHz}(141 \mathrm{~s}$ and $70 \mathrm{~s}$ ) being dominant. Interestingly, these two components are harmonically related, the second being twice the frequency of the first. This is illustrated in Fig. 8a, a time series of the optical intensity at a latitude of $77.1^{\circ}$ during wave packet IV: the double-humped peaks of the oscillation are characteristic of frequency-doubling. Again, an approximate $180^{\circ}$ phase change over the latitude range is observed in each frequency component. Wave packets I, III, and $\mathrm{V}$ contain the frequency components $6 / 12 \mathrm{mHz}, 10 / 15 \mathrm{mHz}$, and $10 \mathrm{mHz}$, respectively.

The MSP observations allow no estimation of the east-west extent of these auroral forms. This information can be gained from white light all-sky camera images from Longyearbyen, collected during the period of interest. Four typical examples, from 1222 UT and 1230, 1231 and 1232 UT (during and at the end of wave packet IV), are illustrated in Fig. 9, rotated such that geomagnetic north and east are directed towards the top and left, respectively; the last three images form a time series, with a time step of $60 \mathrm{~s}$. The bright feature to the extreme SW of each image is light contamination. The times of these four images have been chosen somewhat arbitrarily, though they are from the end of the period of study when the green line emission intensity dominated over that of the red line (see Fig. 2) and hence the optical emission originated predominantly from a single altitude only. The optical features corresponding to the MSP observations are significantly extended in azimuth, though are not exactly $L$-shell aligned, sloping slightly from SE to NW. Multiple auroral forms are present simultaneously, spaced azimuthally along approximately constant latitude, producing a "twill" pattern. Assuming an emission altitude near $200 \mathrm{~km}$, the azimuthal separation of the features (the azimuthal "wavelength") can be estimated to be of the order of $500 \mathrm{~km}$.

\subsection{Ground-based magnetometer observations}

Ground-based magnetometer observations from the interval of interest indicate the presence of quasicontinuous, though low amplitude, wave activity. Figure 10 illustrates the $X$ and $Y$ component magnetograms from a high-latitude magnetometer station close to the location of the optical aurora, HOR, and a mid-latitude station, NUR. Wave activity is most evident in the $X$ component of the mid-latitude station. This wave activity is perhaps most clear between 1200 UT and 1230 UT, around the time of wave packet IV in the optical observations (see Figs. 8 and 10), and this interval has been selected for more detailed analysis. Figure 11a and c illustrates the $X$ and $Y$ component magnetograms from the latitudinal IMAGE chain between 1200 UT and 1230 UT. The data have been high-pass filtered with a cut-off period of $600 \mathrm{~s}$, to suppress frequencies below approximately $2 \mathrm{mHz}$. Self-normalised spectra for each station and component are illustrated in Fig. $11 \mathrm{~b}$, d. The spectra indicate that at the higher latitude stations, especially LYR and HOR, two frequency components near 3.5 to $4 \mathrm{mHz}$ and $7 \mathrm{mHz}$ (indicated by vertical dotted lines) are present in both $X_{\mathrm{mag}}$ and $Y_{\mathrm{mag}}$. A spectral peak is also observed near $2 \mathrm{mHz}$, though its proximity to the cut-off frequency of the applied filter places its significance in doubt; the only time at which such a frequency (equivalent to a period of 7 to $8 \mathrm{~min}$ ) is clearly apparent in the magnetograms is after 1210 UT (as seen in the $Y$ component of HOR, Fig. 10). The lower frequency components also dominate the magnetograms over a broad range of latitudes. At the lowest latitude stations, OUJ, HAN, and NUR, the $7 \mathrm{mHz}$ frequency component is again observed, predominantly in the $X_{\text {mag }}$ magnetograms. At both higher (NAL, LYR, HOR) and lower (OUJ, HAN, NUR) latitudes, the latitudinal phase variation of the two frequency components, especially the $7 \mathrm{mHz}$ component, is in the same sense as the phase variation observed in the optical emission, with phase lag increasing with increasing latitude. 


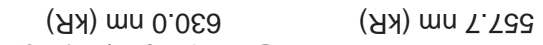

மִ

$0+\infty \sim$

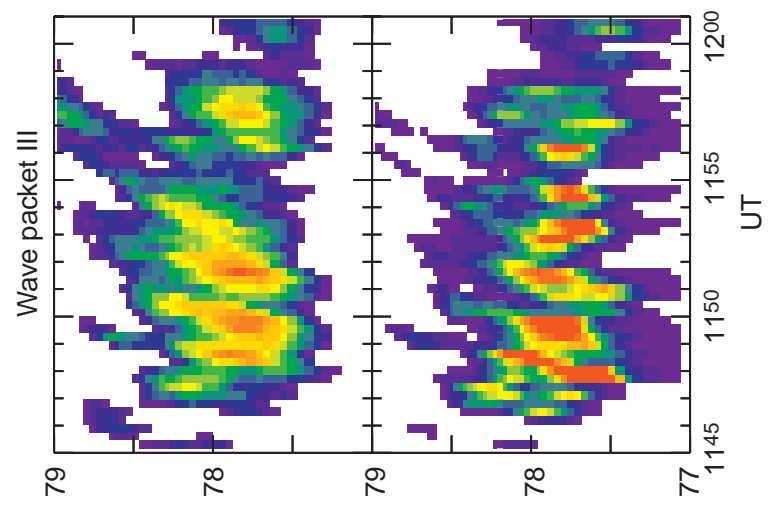

(уу) шu 0.089

(уУ) $\mathrm{mu} \angle \cdot \angle G S$

ஸั

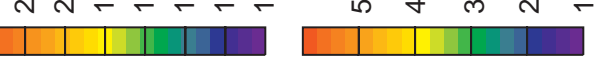

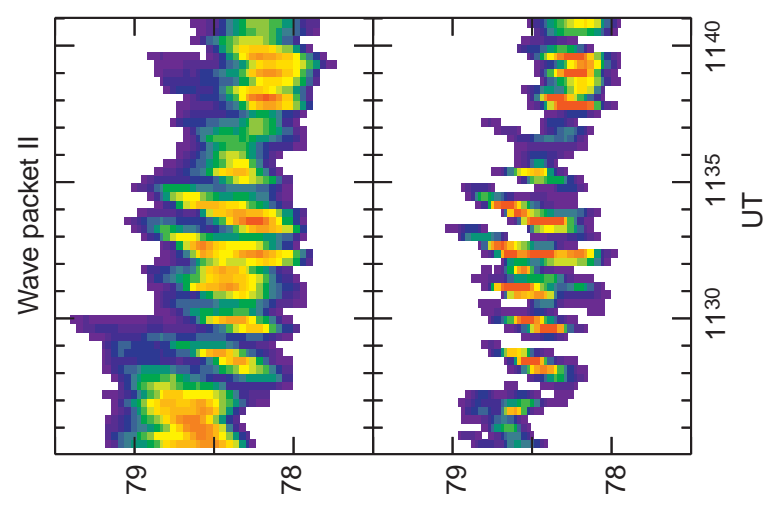

(уу્) سu L'LSS

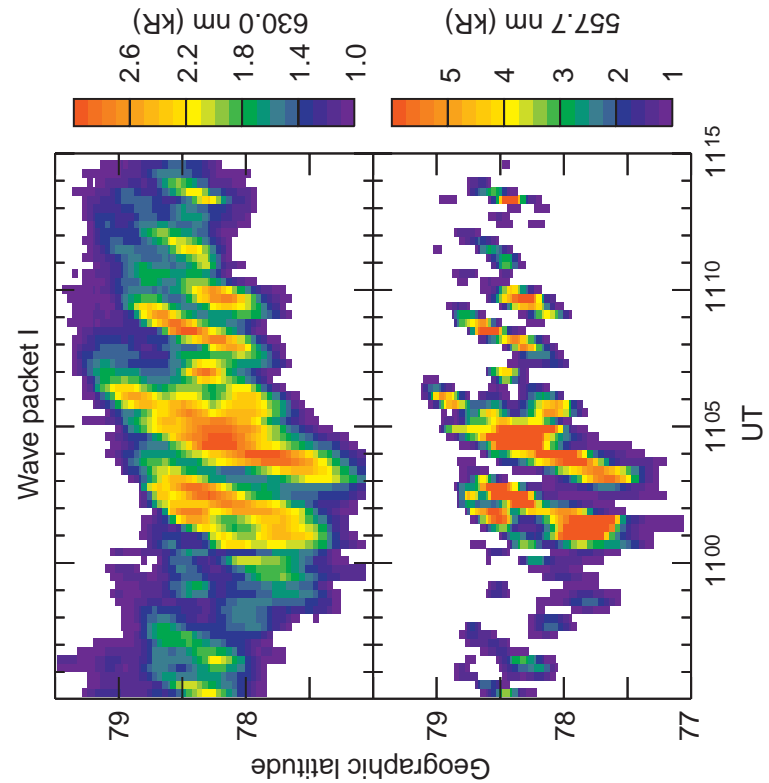

(уу્ર) mu L'LSG

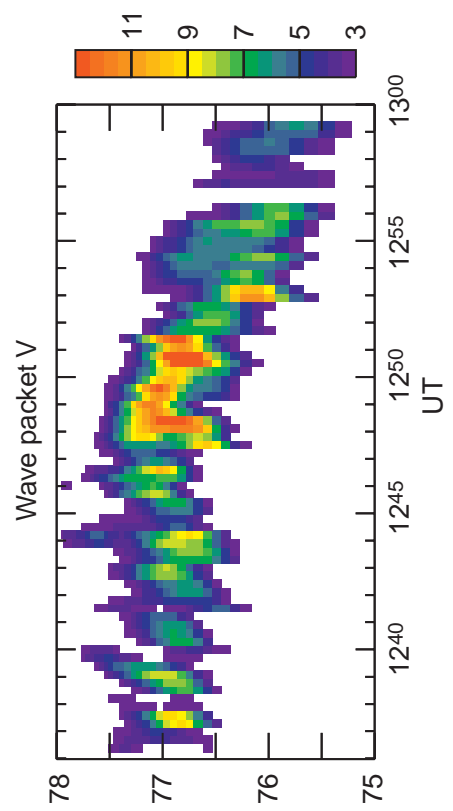

(уу) $\mathrm{mu} \angle \cdot \angle G S$

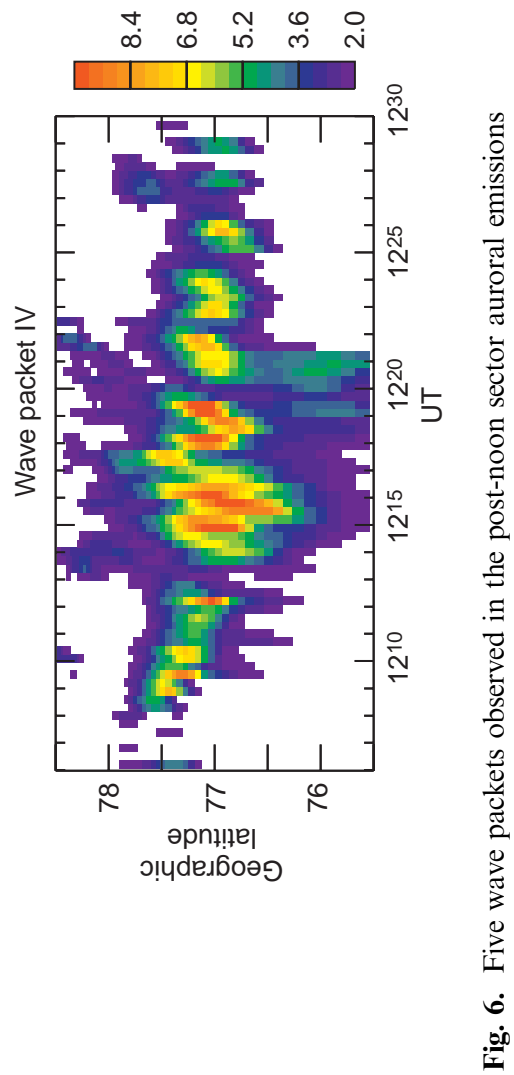




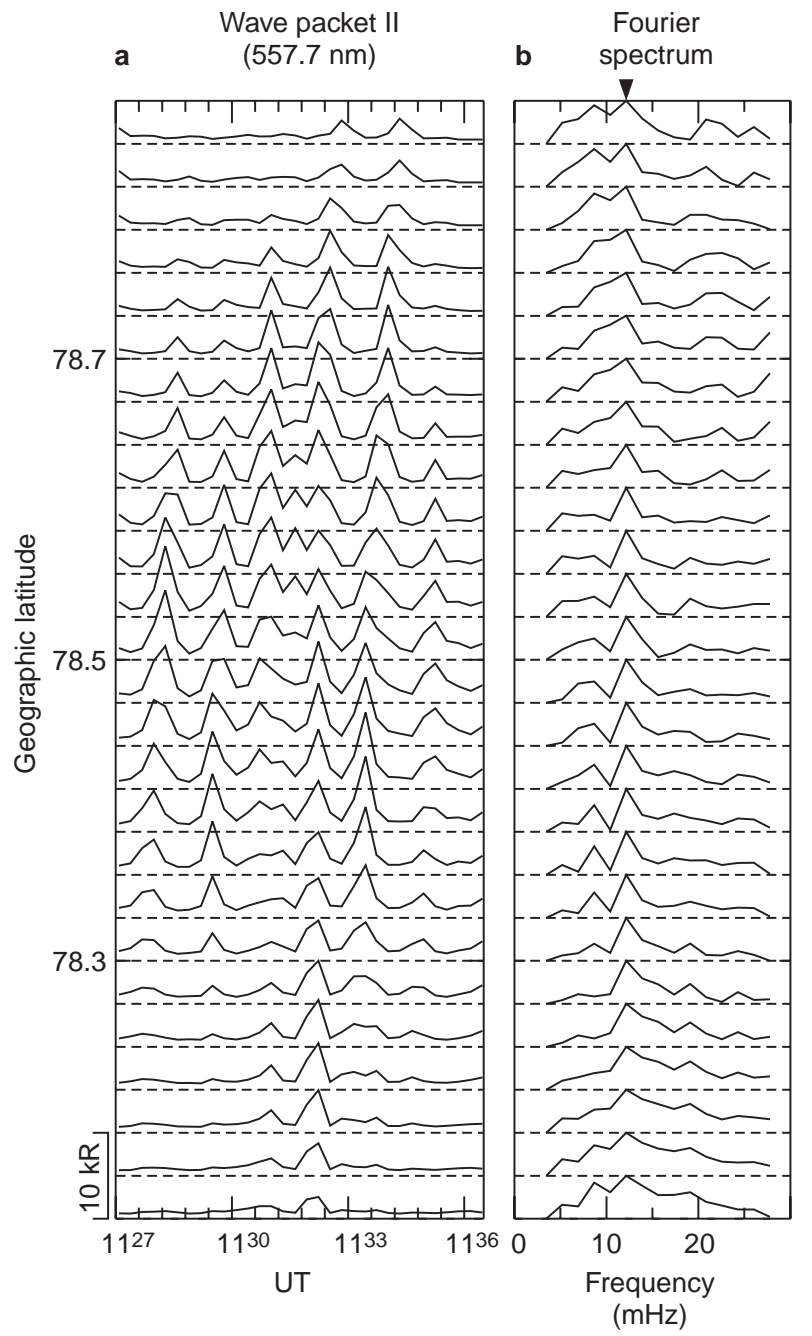

4 Discussion

The observations presented can be summarised as follows. During an interval of relatively stable IMF $B_{z}<0 \mathrm{nT}$ and $B_{y} \gtrsim 0 \mathrm{nT}$ conditions, HF radar observations indicate that the dayside convection pattern consisted of a convection flow reversal near a latitude of $76^{\circ}$ CGMLAT in the post-noon sector, and poleward and westward flow in the local noon sector. In the noon sector, the radar backscatter had high spectral width which, together with simultaneous large poleward velocities, has previously been interpreted as the ionospheric footprint of the cusp region (Baker et al., 1990, 1995). Prior to 1030 UT, when the Ny Ålesund MSP was located underneath this region, "midday gap" aurora were observed (Dandekar and Pike, 1978). Such an auroral configuration is generally attributed to precipitation of magnetosheath origin, consistent with the cusp interpretation of the radar measurements. Moreover, low-altitude particle measurements indicated that this region corresponded to mantle precipitation with a significant flux of low energy ions, indicative of recently reconnected field lines. In the post-noon sector, the lowaltitude particle observations indicated that the radar backscatter equatorward of the convection reversal

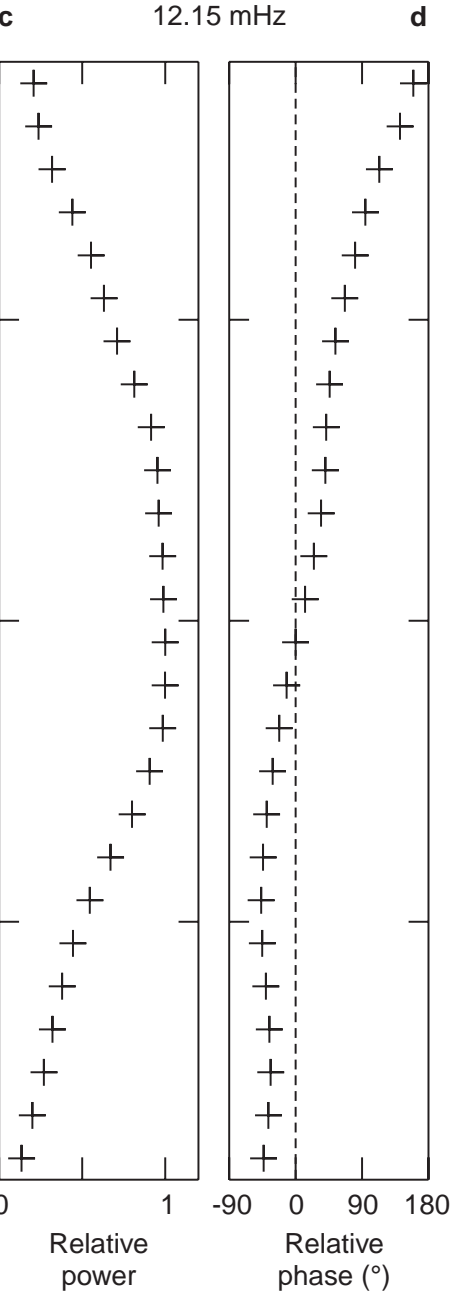

Fig. 7a-d. Spectral analysis of the green line observations of wave packet II boundary, in the sunward return flow region, was colocated with BPS precipitation on closed field lines. Poleward of this, in the antisunward flow region, mantle precipitation was observed, indicating open field lines. No radar backscatter was observed in the CPS precipitation region. A continuous (though pulsating) optical auroral feature was observed in both red and green lines in the post-noon sector, co-located with the convection return flow backscatter region and BPS precipitation; this optical feature was present between 1030 UT and 1300 UT (when observations ceased), corresponding to between 1330 MLT and 1600 MLT. No significant optical emission was observed in the CPS or mantle precipitation regions.

The significance of boundaries in HF radar backscatter has been discussed previously. Milan et al. (1998) reported that in the dayside auroral zone both the equatorward and poleward edges of radar backscatter are in general, independent of instrumental limitations such as propagation mode, and hence must correspond to geophysical boundaries, though the nature of these boundaries was not elucidated. Furthermore, Rodger et al. (1995) and Milan et al. (1999) demonstrated the co-location of dayside red line optical aurora and the equatorward portion of radar backscatter, as shown in 


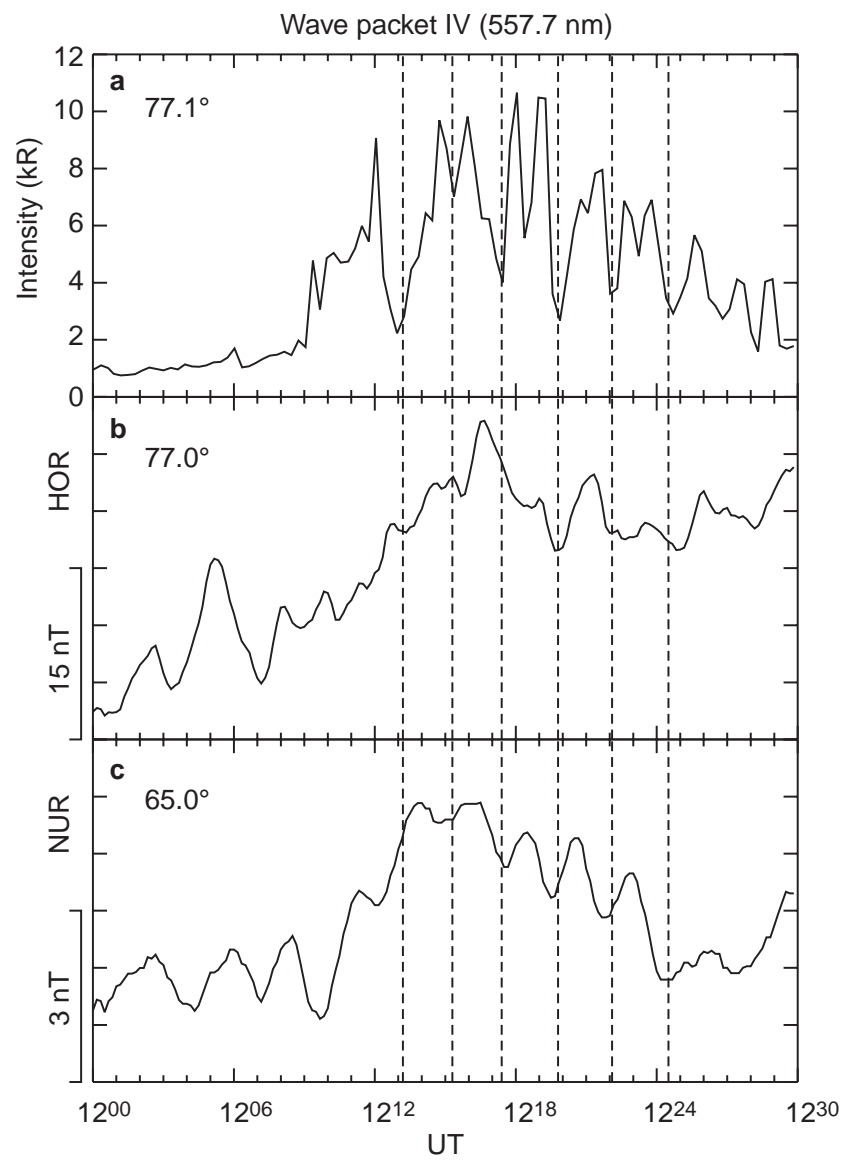

Fig. 8. a Time series of the green line optical intensity at a geographic latitude of $77.1^{\circ}$ observed during wave packet IV. Unfiltered $X$ component magnetograms from b a high-latitude (HOR) and $\mathbf{c}$ mid-latitude (NUR) station. Vertical dashed lines are added to aid comparison with the eye

the present study, again indicating a concrete relationship between radar aurora and dayside precipitation regions. The present study suggests that the equatorward boundary of post-noon optical emission and radar backscatter corresponds to the transition from CPS to BPS precipitation. Radar aurora are also observed in regions of mantle precipitation, and it is interesting to note that the observed spectral width of the backscatter appears to increase with the flux of low energy ions.

In general, red line optical emissions are excited by precipitation of low energy (of order $100 \mathrm{eV}$ ) electrons, consistent with the energy characteristics of unaccelerated magnetosheath plasma of cusp/cleft origin on newly-reconnected field lines; hence in the noon sector the equatorward boundary of the red line aurora has been identified as the open/closed field line boundary (e.g. Lockwood et al. 1993). Away from noon, however, the aurora typically takes the form of a continuous arc, as observed in the present case. Sandholt et al. (1998) termed this optical feature "type 7 aurora" in the postnoon sector, and concluded that, if located in a region of sunward convection, it was the optical manifestation of BPS precipitation. This is consistent with our observations. Hence, the open/closed field line boundary occurs at the poleward edge of the aurora, in our case observed as the transition between BPS and mantle precipitation, closely co-located with the convection reversal boundary. A similar correspondence between the red line aurora and the nightside polar cap boundary has been reported by Blanchard et al. (1995).

Potemra (1994) identified LLBL/BPS precipitation as the region 1 Birkeland current system, which in the postnoon sector comprises an upward field-aligned current (FAC), carried by precipitating electrons. This FAC is an integral component of the magnetospheric/ionospheric convection process, balancing the non-zero divergence of the convection electric field in the vicinity of the post-noon convection reversal. The fundamental finding of the present study is the highly periodic modulation of the optical emission intensity associated with this current system. This modulation has a period near 1 to $2 \mathrm{~min}$, within the Pc4 ULF magnetohydrodynamic wave period range. The latitudinal phase variation of the modulation gives the optical aurora the appearance of poleward-moving auroral forms (PMAFs) when viewed with a meridian-scanning photometer. These features are similar in nature to observations of Pc5 ULF waves in VHF radar measurements (e.g. Walker et al., 1979), where the latitudinal phase variation, a $180^{\circ}$ phase change across the latitude of the pulsation amplitude maximum, is found to be consistent with field line resonance (FLR) structures (e.g. Orr and Hanson, 1981). The PMAFs in the present study appear to be between $20 \mathrm{~km}$ and $50 \mathrm{~km}$ in latitudinal extent and progress between $50 \mathrm{~km}$ and $150 \mathrm{~km}$ along the MSP meridian. The auroral forms are extended approximately $1000 \mathrm{~km}$ to $1500 \mathrm{~km}$ in the east-west direction, similar to previous observations of systems of multiple discrete arcs located within the region 1 FAC system (Moen et al., 1994, 1995), and slope slightly from SE to NW. Multiple auroral forms have an azimuthal separation of approximately $500 \mathrm{~km}$, giving a "twill" appearance. For consistency with their apparent poleward motion along the meridian, these forms must also have an eastward (antisunward) phase motion; this motion is indicated by lettering in the last three panels of Fig. 9. For a pulsation with a period of $120 \mathrm{~s}$ the velocity of this phase motion would be approximately $4 \mathrm{~km} \mathrm{~s}^{-1}$; when observed with insufficient temporal resolution, this phase motion will not be apparent. Overall, then, the observed phase structure of the aurora is consistent with an FLR with azimuthal wave number $m \approx 20$ to 30 . The relationship between the optical observations and ULF FLR events is further strengthened by the presence of multiple harmonic frequency components within the Fourier spectrum of the modulation of the emission intensity.

To draw a more direct link between ULF wave activity and the pulsating aurora, ground-based magnetometer measurements were compared with the optical observations. In general, it was found that clear pulsations were not apparent in the magnetograms, especially at auroral latitudes. This is perhaps to be expected as ground magnetometers integrate over a large area of the sky, of order $100 \mathrm{~km}$ in spatial extent (Hughes and Southwood, 1976), comparable with the latitudinal 

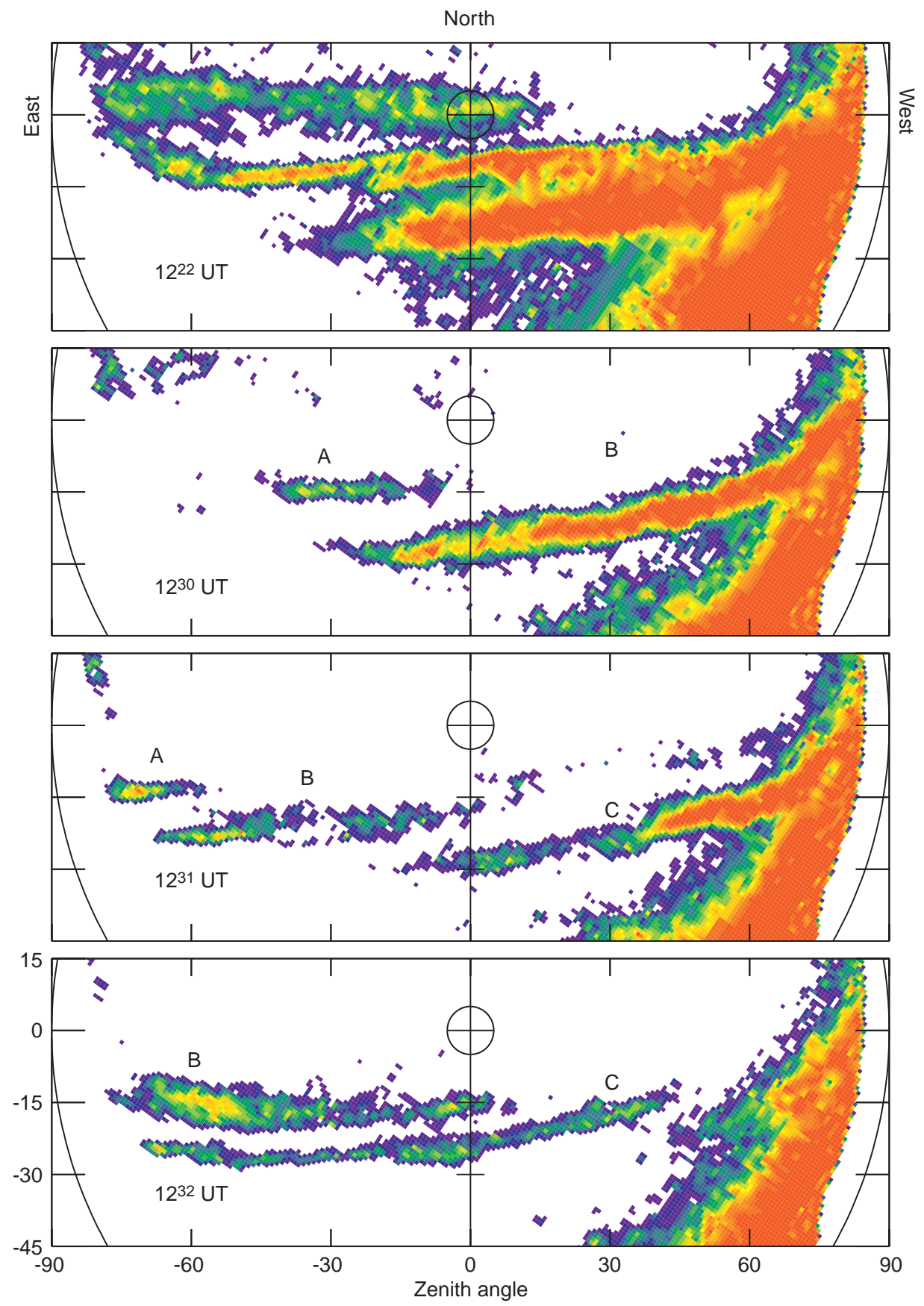

Fig. 9. Four white light Longyearbyen ASC images from wave packet IV, on an arbitary intensity scale. The images have been rotated such that geomagnetic north is directed towards the top of each panel. The last three images form a time series with $60 \mathrm{~s}$ time step; the letters $A$ to $C$ indicate the probable relationship between the auroral features in each image width of the pulsating aurora, and hence considerable phase-mixing will occur. The MSP observations do not suffer from this drawback, and hence the latitudinal phase and amplitude variation of the wave is clear. The clearest example of simultaneous magnetic and optical modulation occurred in the case of wave packet IV, between approximately 1205 UT and 1225 UT (see Fig. 8). At this time, the frequency components $7.1 \mathrm{mHz}$ and $14.1 \mathrm{mHz}$ were present in the aurora, and 3.5 to $4 \mathrm{mHz}$ and $7 \mathrm{mHz}$ (and possibly $2 \mathrm{mHz}$ ) were observed on the ground at the latitude of the aurora. Clearly, a close harmonic relationships exists between the optical and magnetometer observations. The optical frequency components appear to be close to twice the frequency of the magnetometer frequency components. It is also possible that the higher frequency component of the magnetic variations is a harmonic of the lower frequency component. This will be discussed in more detail later, but first it is interesting to compare the magnetometer estimate of $m$ with that determined from the optical observations. The stations HOR and HOP are separated in longitude by approximately $10^{\circ}$, and the phase measurements of the $7 \mathrm{mHz}$ frequency component indicate that HOP leads HOR by some $90^{\circ}$ in the $\mathrm{Y}$ component. The usual interpretation of this phase lag would be westward phase propagation with $m \approx 9$, which is not consistent with the auroral observations of eastward propagation with $m \approx 20$ to 30 . Conversely, 


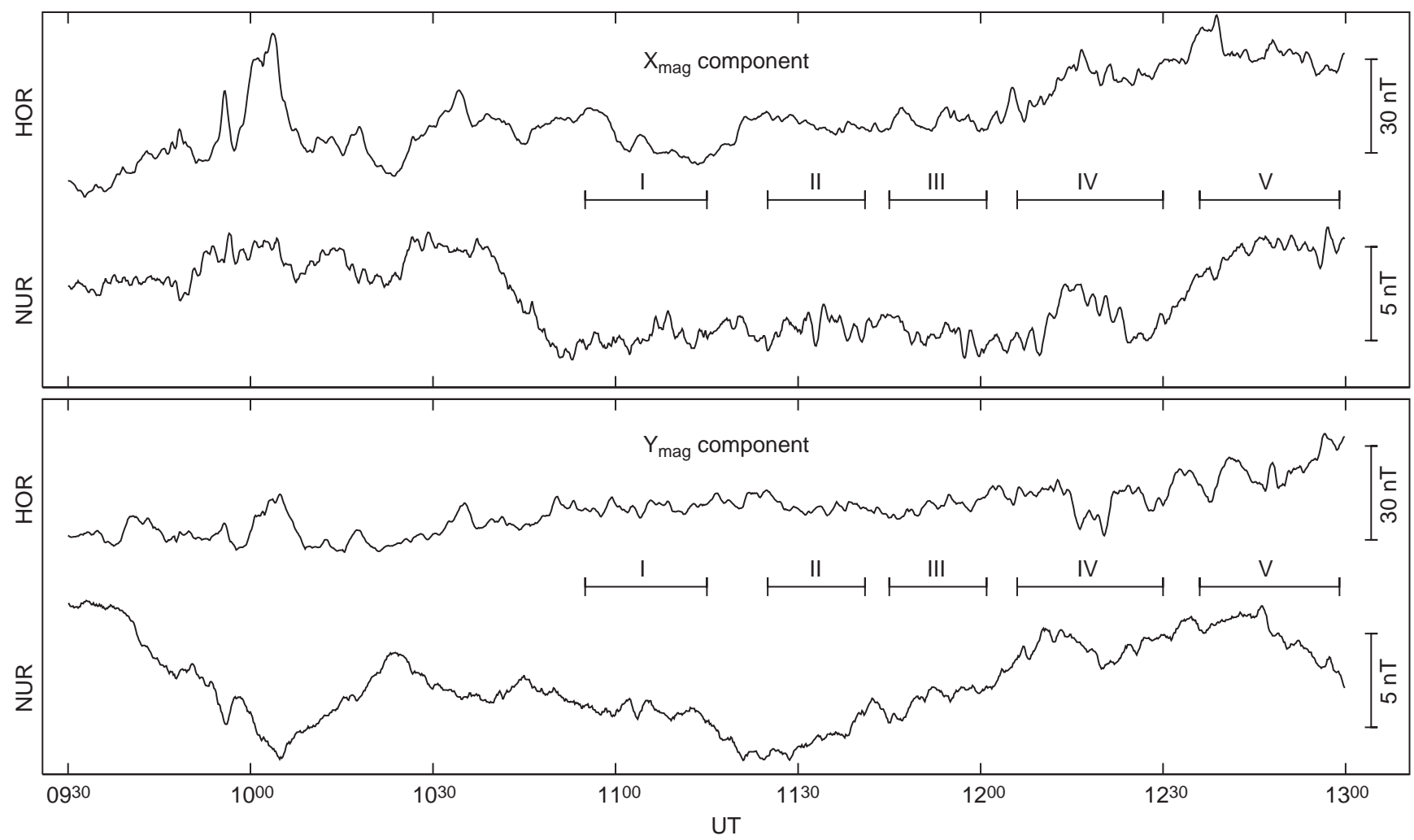

Fig. 10. $X$ and $Y$ component magnetograms from the study interval for a high-latitude (HOR) and mid-latitude (NUR) station

however, the magnetometer measurements could be interpreted as HOP lagging HOR by approximately $270^{\circ}$, giving an estimate of $m \approx 27$ and eastward phase motion, this time consistent with the optical observations. This shows that high $m$ number waves can be misidentified when sampled with too few magnetometers.

The fundamental eigenperiod of FLRs, essentially standing waves along closed quasi-dipolar magnetic field lines, is twice the Alfvén travel time between conjugate ionospheres. At the latitude of, say, HOR the fundamental period is calculated to be of the order of several minutes (Orr and Hanson, 1981) and is observed to be between 5 and $10 \mathrm{~min}$ (Poulter et al. 1984). Hence, the 3.5 to $4 \mathrm{mHz}$ frequency component of the magnetogram oscillation could be consistent with either the fundamental mode or second harmonic mode. In the latter case, the fundamental component would be expected near $1.7 \mathrm{mHz}$ (which possibly corresponds to the $2 \mathrm{mHz}$ component observed in Fig. 11) and the higher frequency component would represent the fourth harmonic. If the observed frequency components are indeed the even harmonic modes of the field line resonance, this has implications for the potential optical emission modulation mechanism, as will be discussed later. Unfortunately, the present measurements do not allow the exact harmonic structure of the observed ULF wave to be determined.

Davidson (1990) stated that ULF wave activity associated with the pulsating aurora is driven by the modification of the local ionosphere in response to the modulated precipitation. This is not consistent with the present observations, in which the aurora are modulated at harmonics of the local FLR fundamental frequency, i.e. appear to be driven by the wave. It is conjectured that a narrow-band source with a compressional component, such as a cavity mode, is responsible for the excitation of the FLR pulsation. This is suggested as at mid-latitudes, near NUR, HAN and OUJ, where the standing wave fundamental is approximately $7 \mathrm{mHz}$ (Orr and Hanson, 1981; Orr, 1984), close to the higher harmonic component of the high-latitude wave, a secondary maximum in the amplitude of this frequency component is observed. At these latitudes also, the latitudinal phase variation and the dominance of the modulation in the $X$ component are characteristic of FLR structures. The cavity mode, then, couples to shear Alfvén waves (FLRs) at the latitudes where the cavity resonance frequency matches the standing wave fundamental (at mid-latitudes) and a harmonic of the standing wave fundamental (at high-latitudes). This situation is similar to the mechanism proposed by $\mathrm{Xu}$ et al. (1993), in which a cavity mode couples both to a mid-latitude FLR and an FLR at the cavity boundary at highlatitudes. The cavity resonance itself could be driven by several sources, including Kelvin-Helmholtz waves at the magnetopause or impulsive reconfigurations of the dayside magnetosphere, for instance through the occurrence of magnetopause flux transfer events (FTEs). That some of the optical wave packets, especially packets I, III, and IV (see Fig. 6), have the appearance of damped harmonic oscillations in re- 

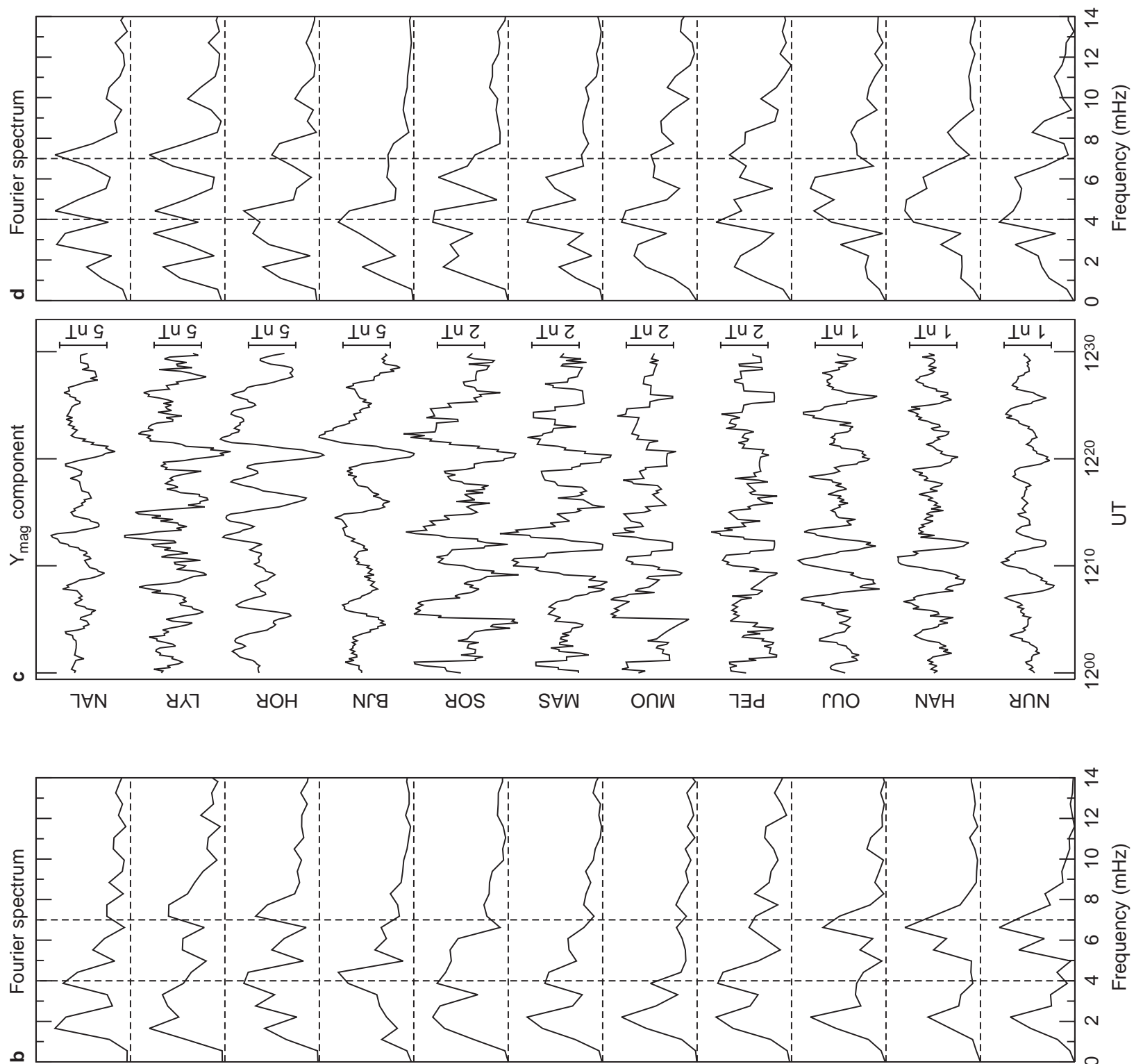

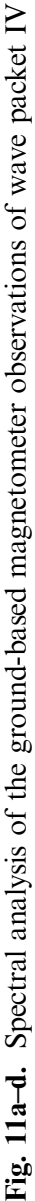

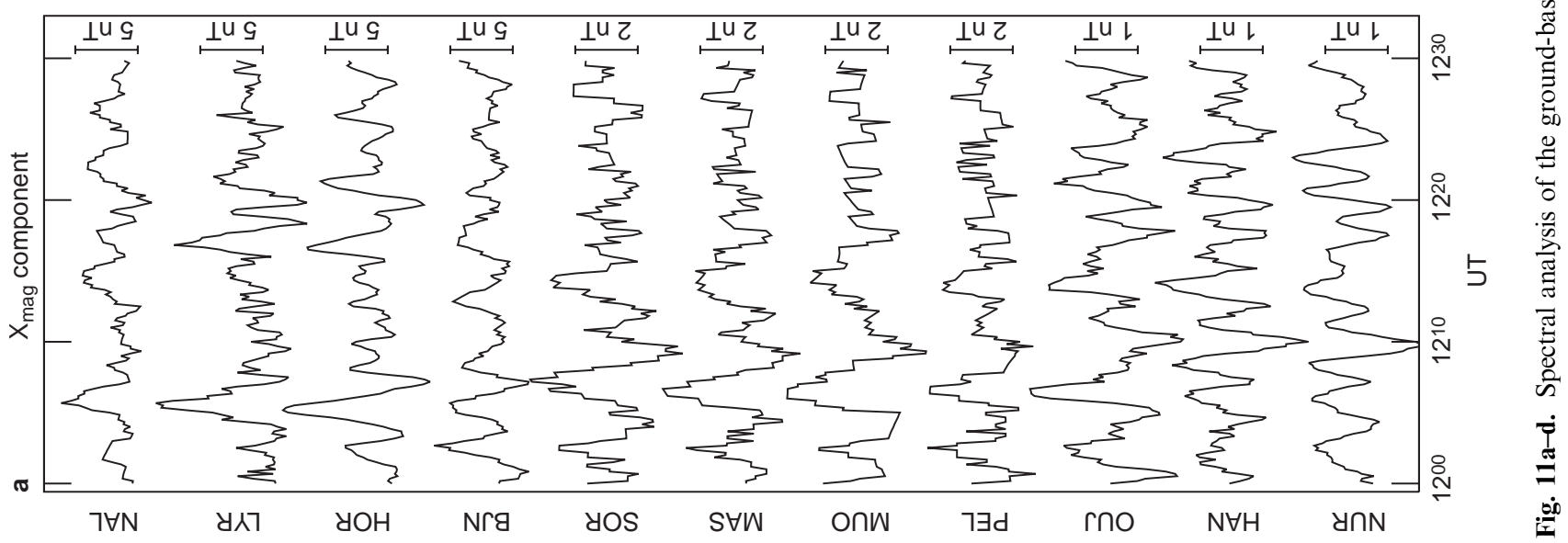


sponse to impulsive forcing lends credence to the latter mechanism. In further support for this mechanism, the enhancement in the optical emission intensity wave amplitude at 1211 UT during wave packet IV (Figs. 6 and 8), corresponds to an increase in the unfiltered $X$ component of the magnetic field at both high- and mid-latitudes (Fig. 8), possibly indicating a slight reconfiguration of the magnetosphere. Following this, a 7 to $8 \mathrm{~min}$ period fluctuation is observed in some highlatitude magnetograms (see HOR $Y$ component in Fig. 10); this period is close to the typical repetition period of FTEs. It has been shown previously that the occurrence of FTEs is often accompanied by Pc5 ULF pulsations on closed field lines, Walker et al. (1986), Øieroset et al. (1996, 1997), and Lee et al. (1988) proposed a mechanism by which these could be excited.

The mechanism through which the optical emission intensity is modulated by the ULF wave is unclear. Several possibilities exist, including pitch angle scattering of trapped particles (e.g. Coroniti and Kennel, 1970), or field-aligned acceleration of electrons by electron inertia waves or kinetic Alfvén waves, produced through mode-conversion from the shear Alfvén standing waves (Hasegawa, 1976; Goertz, 1984). The mechanism of Coroniti and Kennel (1970) relies on the ULF waves being even harmonic modes, which is indeed a possibility (see earlier). Interestingly, the optical emission appears to be modulated at frequencies twice those present in the magnetic variations. Several workers have advocated ULF waves as the driving mechanism for auroral arc formation (e.g. Samson et al., 1991; Xu et al., 1993; Moen et al., 1994). In the present case, the auroral arc in question is the optical manifestation of the region 1 current system, and hence its generating mechanism is of great importance with respect to the excitation of magnetospheric/ionospheric convection. The radar scan employed during the present study did not have sufficient time resolution to resolve the ionospheric plasma drift response to the ULF wave activity. However, Milan et al. (1999) reported on similar observations, from 17 December, 1995, the previous day to the present study, in the post-noon sector with a radar scan that allowed $14 \mathrm{~s}$ time resolution on beam 9. Enhancements of the convection return flow plasma drift velocity were co-located with $2 \mathrm{~min}$ quasi-periodic enhancements of the auroral emission intensity (see their Fig. 6), indicating a close relationship between this wave activity and convection processes. On 5 days of the 8-day experimental campaign from which the measurements presented in this study were taken, under a variety of IMF and solar wind conditions, the post-noon region 1 optical arc appeared modulated in a quasi-periodic manner, confirming the ubiquity and importance of this phenomenon. The observation of short-period quasi-periodic modulations of the convection velocity will perhaps in future be of use in determining the locations of important magnetospheric boundaries, such as the open/closed field line boundary.

Two final points must be addressed regarding the present observations. The first concerns the altitude of emission of the red and green line optical intensity. The assumed emission altitude of the red line, $300 \mathrm{~km}$, is consistent with previous studies and achieves excellent agreement between the MSP and radar observations (Fig. 2). To provide a fit between the red and green line observations, and again an excellent correspondence can be achieved (see Fig. 6), a green line emission altitude of $200 \mathrm{~km}$ must be employed, somewhat higher that has previously been assumed (see for instance Lockwood et al. (1993) in which the emission altitude is assumed to be below $130 \mathrm{~km}$ ). However, this somewhat elevated emission altitude appears consistent in producing correspondence between red and green line dayside optical features throughout the eight day campaign from which the present observations were taken. This indicates that care must be exercised in studies of this nature, certainly in studies in which the relative locations of the red and green line emission are attributed geophysical significance, as is the case in Lockwood et al. (1993), as the assumed emission altitude is of critical importance in determining the mapped location of the observations. In the present study, an assumed emission altitude of $120 \mathrm{~km}$ would place the green line observations poleward of the red line features, by an amount dependent on the true location of the aurora relative to $\mathrm{Ny}$ Alesund, but by over $1^{\circ}$ of latitude in the case of wave packet V. That the red and green optical emissions are truly co-located can be surmised from periods when the aurora are overhead the MSP $\left(78.9^{\circ} \mathrm{N}\right)$, for instance during wave packet I (see Fig. 6), and the mapping is independent of the assumed emission altitudes.

The second point is with respect to confusion that could arise in studies of magnetopause flux transfer events. The optical signature of an FTE at the ionospheric footprint of the cusp region is a poleward-moving auroral form (see Farrugia et al. (1998), and Fasel (1995) and references therein), very similar in nature to the MSP observations of the present study. However, the occurrence of flux transfer events is not expected to be periodic in nature, and is generally accepted to have a mean repetition rate of approximately $8 \mathrm{~min}$ (though Lockwood and Wild (1993) reported that the distribution of intervals between magnetopause signatures of FTEs was highly skewed, with a mode near $3 \mathrm{~min}$ ). It is possible that the superficial similarity between the optical signatures of the two phenomena and the proximity of the cusp and region 1 current systems has lead to some confusion, and statistical studies of FTE occurrence based on optical observations could be contaminated by short-period ULF wave events.

\section{Conclusions}

The emission intensity of the post-noon dayside aurora associated with the region 1 FAC system is commonly modulated in a quasi-periodic manner with periods near $2 \mathrm{~min}$, on field lines just equatorward of the open/closed 
field line boundary. This modulation appears related to ULF magnetohydrodynamic wave activity; several harmonics of the fundamental field line resonance eigenfrequency can be detected by ground magnetometer stations located underneath the aurora. The modulation of the auroral emission intensity has frequency components equal to twice that of the ULF wave harmonics. This wave activity also causes modulation of the convection return flow plasma drift velocity. The importance of this wave activity in the excitation of magnetospheric/ionospheric convection must not be over-looked.

Acknowledgements. CUTLASS is supported by the Particle Physics and Astronomy Research Council (PPARC grant PPA/R/R/ 1997/00256), UK, the Swedish Institute for Space Physics, Uppsala, and the Finnish Meteorological Institute, Helsinki. SEM is supported on PPARC grant PPA/G/O/1997/000254. The work has been supported by Norwegian Research Council and UNIS grant 9/963. The IMAGE magnetometer data employed were collected as a German-Finnish-Norwegian-Polish project conducted by the Geophysical Research Division of the Finnish Meteorological Institute (FMI/GEO). The WIND IMF observations were provided by R. P. Lepping of the Laboratory for Extraterrestrial Physics, NASA/Goddard Space Flight Centre, MD, USA. The DMSP particle data were obtained through the World Data Centre-A in Boulder, Colorado, USA; D. A. Hardy and colleagues of the Air Force Research Laboratory (formally the Air Force Geophysics Laboratory) designed and built the SSJ/4 particle instrument. P. T. Newell of The Johns Hopkins University Applied Physics Laboratory, Maryland, USA, provided the boundary identifications based on the DMSP observations. The Longyearbyen ASC images were provided by T. J. Hallinan of the Geophysical Institute, UAF, Alaska.

Topical Editor K.-H. Glassmeier thanks H. Opgenoorth and H. Lühr for their help in evaluating this paper.

\section{References}

Baker, K. B., and S. Wing, A new magnetic coordinate system for conjugate studies at high latitude, J. Geophys. Res., 94, 91399143, 1989.

Baker, K. B., R. A. Greenwald, J. M. Ruohoniemi, J. R. Dudeney, M. Pinnock, P. T. Newell, M. E. Greenspan, and C.-I. Meng, Simultaneous HF radar and DMSP observations of the cusp, Geophys. Res. Lett., 17, 1869-1871, 1990.

Baker, K. B., J. R. Dudeney, R. A. Greenwald, M. Pinnock, P. T. Newell, A. S. Rodger, N. Mattin, and C.-I. Meng, HF radar signatures of the cusp and low-latitude boundary layer, J. Geophys. Res., 100, 7671, 1995.

Blanchard, G. T., L. R. Lyons, J. C. Samson, and F. J. Rich, Locating the polar cap boundary from observations of $6300 \AA$ auroral emission, J. Geophys. Res., 100, 7855-7862, 1995.

Coroniti, F. V., and C. F. Kennel, Electron precipitation pulsations, J. Geophys. Res., 75, 1279-1289, 1970.

Dandekar, B. S., and C. P. Pike, The midday discrete auroral gap, J. Geophys. Res., 83, 4227, 1978.

Davidson, G. T., Pitch-angle diffusion and the origin of temporal and spatial structures in morningside aurorae, Space Sci. Rev., 53, 45-82, 1990.

Farrugia, C. J., P. E. Sandholt, W. F. Denig, and R. B. Torbert, Observation of a correspondence between poleward-moving auroral forms and stepped cusp ion precipitation, J. Geophys. Res., 103, 9309-9315, 1998.

Fasel, G. J., Dayside poleward moving auroral forms: a statistical study, J. Geophys. Res., 100, 11891, 1995.
Goertz, C. K., Kinetic Alfvén waves on auroral field lines, Planet. Space Sci., 32, 1387, 1984.

Greenwald, R. A., K. B. Baker, J. R. Dudeney, M. Pinnock, T. B. Jones, E. C. Thomas, J.-P. Villain, J.-C. Cerisier, C. Senior, C. Hanuise, R. D. Hunsucker, G. Sofko, J. Koehler, E. Nielsen, R. Pellinen, A. D. M. Walker, N. Sato, and H. Yamagishi, DARN/SuperDARN: a global view of the dynamics of highlatitude convection, Space Sci. Rev., 71, 761-796, 1995.

Hasegawa, A., Particle acceleration by MHD surface wave and formation of aurora, J. Geophys. Res., 81, 5083, 1976.

Hughes, W. J., and D. J. Southwood, The screening of micropulsation signals by the atmosphere and ionosphere, J. Geophys. Res., 81, 3234-3240, 1976.

Lee, L. C., Y. Shi, and L. J. Lanzerotti, A mechanism for the generation of cusp region hydromagnetic waves, J. Geophys. Res., 93, 7578-7585, 1988.

Lockwood, M., H. C. Carlson, and P. E. Sandholt, The implications of the altitude of transient $630 \mathrm{~nm}$ dayside auroral emission, J. Geophys. Res., 98, 15 571, 1993.

Lockwood, M., and M. N. Wild, On the quasi-periodic nature of magnetopause flux transfer events, J. Geophys. Res., 98, 59355940, 1993.

Milan, S. E., T. K. Yeoman, and M. Lester, The dayside auroral zone as a hard target for coherent HF radars, Geophys. Res. Lett., 25, 3717-3720, 1998.

Milan, S. E., M. Lester, S. W. H. Cowley, J. Moen, P. E. Sandholt, and C. J. Owen, Meridian-scanning photometer, coherent HF radar, and magnetometer observations of the cusp: a case study, Ann. Geophysicae, 17, 159-172, 1999.

Moen, J., P. E. Sandholt, M. Lockwood, A. Egeland, and K. Fukui, Multiple, discrete arcs on sunward convecting field lines in the 14-15 MLT region, J. Geophys. Res., 99, 6113-6123, 1994.

Moen, J., P. E. Sandholt, M. Lockwood, W. F. Denig, U. P. Løvhaug, B. Lybekk, A. Egeland, D. Opsvik, and E. FriisChristensen, Events of enhanced convection and related dayside auroral activity, J. Geophys. Res., 100, 23 917-23 934, 1995.

Newell, P. T., W. J. Burke, E. R. Sánchez, C.-I. Meng, M. E. Greenspan, and C. R. Clauer, The low-latitude boundary layer and the boundary plasma sheet at low latitude: prenoon precipitation regions and convection reversal boundaries, J. Geophys. Res., 96, 21013-21023, 1991.

Øieroset, M., H. Lühr, J. Moen, T. Moretto, and P. E. Sandholt, Dynamical auroral morphology in relation to ionospheric plasma convection and geomagnetic activity: signatures of magnetopause $\mathrm{X}$ line dynamics and flux transfer events, J. Geophys. Res., 101, 13 275-13 292, 1996.

Øieroset, M., P. E. Sandholt, H. Lühr, W. F. Denig, and T. Moretto, Auroral and geomagnetic events at cusp/mantle latitudes in the prenoon sector during positive IMF By conditions: signatures of pulsed magnetopause reconnection, J. Geophys. Res., 102, 7191-7205, 1997.

Orr, D., Magnetospheric hydromagnetic waves: their eigenperiods, amplitudes and phase variations; a tutorial introduction, J. Geophys., 55, 76-84, 1984.

Orr, D., and H. W. Hanson, Geomagnetic pulsation phase patterns over an extended latitudinal array, J. Atmos. Terr Phys., 43, 899-910, 1981.

Potemra, T. A., Sources of large-scale Birkeland currents, in Physical Signatures of Magnetospheric Boundary Layer Process, 3-27, Kluwer Academic Publishers, The Netherlands, 1994.

Poulter, E. M., W. Allan, J. G. Keys, and E. Nielsen, Plasmatrough ion mass densities determined from ULF pulsation eigenperiods, Planet. Space Sci., 32, 1069-1078, 1984.

Rodger, A. S., S. B. Mende, T. J. Rosenberg, and K. B. Baker, Simultaneous optical and HF radar observations of the ionospheric cusp. Geophys. Res. Lett., 22, 2045, 1995.

Samson, J. C., T. J. Hughes, F. Creutzberg, D. D. Wallis, R. A. Greenwald, and J. M. Ruohoniemi, Observations of a detached, discrete arc in association with field line resonances, J. Geophys. Res., 96, 15683, 1991. 
Sandholt, P. E., C. S. Deehr, A. Egeland, B. Lybekk, R. Viereck, and G. J. Romick, Signatures of the dayside aurora of plasma transfer from the magnetosheath. J. Geophys. Res., 91, 1006310079, 1986.

Sandholt, P. E., C. J. Farrugia, J. Moen, Ø. Noraberg, B. Lybekk, T. Sten, and T. Hansen, A classification of dayside auroral forms and activities as a function of IMF orientation, J. Geophys. Res., 103, 23 325-23 345, 1998.

Sigernes, F., J. Moen, D. A. Lorentzen, C. S. Deehr, R. Smith, M. Øieroset, B. Lybekk, and J. Holtet, SCIFER - height measurements of the midmorning aurora, Geophys. Res. Lett., 23, 1889-1892, 1996.
Walker, A. D. M., R. A. Greenwald, W. F. Stuart, and C. A. Green, Stare auroral radar observations of Pc5 geomagnetic pulsations. J. Geophys. Res., 84, 3373-3388, 1979.

Walker, A. D. M., R. A. Greenwald, and K. B. Baker, HF radar observations of pulsations near the magnetospheric cusp, J. Geophys. Res., 91, 8919-8928, 1986.

Xu, B.-L., J. C. Samson, W. W. Liu, F. Creutzberg, and T. J. Hughes, Observations of optical aurora modulated by resonant Alfvén waves, J. Geophys. Res., 98, 11 531-11 541, 1993. 